\title{
Laryngeal Mucous Salivary Gland
}

National Cancer Institute

\section{Source}

National Cancer Institute. Laryngeal Mucous Salivary Gland. NCI Thesaurus. Code C49244.

One of the many muciparous glands within the mucous membrane of the larynx. 